\title{
Severe Craniocerebral Traumas From Television-Tip-Over in Children
}

\author{
Murteza Cakir ${ }^{1}$ (D), Cagatay Calikoglu ${ }^{1}$ (D) Oktay Ozpolat ${ }^{2}$ (D) \\ 'Department of Neurosurgery, Ataturk University School of Medicine, Erzurum, Turkey \\ ${ }^{2}$ Department of Emergency Medicine, Ataturk University School of Medicine, Erzurum, Turkey
}

Cite this article as: Cakir M, Calikoglu C, Ozpolat O. Severe Craniocerebral Traumas from Television-Tip-Over in Children. Eurasian J Emerg Med. 2018; 17 (3): 129-32.

\begin{abstract}
Aim: To present a detailed description and to assess outcomes of trauma caused by televisions (TVs) toppling onto children during the last 17 years

Materials and Methods: The records of 34 patients aged 0-16 years with TV-related serious head injuries presenting to a tertiary hospital during the last 17 years were retrospectively reviewed. From the hospital's file recordings, authors retrieved data about demographic information; Pediatric Glasgow Coma Scale (PGCS) score; length of hospital stay; injuries supervened to the scalp, cranium, or brain; and Glasgow Outcome Scale score.

Results: Thirty-four children were injured following TV falls between January 2000 and December 2017. Of these, 44.1\% ( $n=15$ ) were toddlers aged 2-3 years, and $73.5 \%(n=25)$ were girls. All of the injuries occurred at home, and all of them had skull fractures. Five children (14.3\%) had a PGCS of $<7$, and seven patients (20.6\%) died in the hospital. The median duration of hospitalization was 2 days (minimum 1 and maximum 27), and 23 patients (67.6\%) were discharged home with a good outcome.

Conclusion: These data indicate that TV-related injuries are still an important source of hazard, especially for toddlers. TV-related home accident prevention programs should include awareness-raising campaigns for parents as well as setting production and construction standards for the industry.
\end{abstract}

Keywords: Home accidents, head trauma, television, children

ORCID IDs of the authors: M.C. 0000-0001-6186-5129; C.C. 0000-0002-8569-494X; O.0. 0000-0002-9445-0015.

\section{Introduction}

Research has shown that watching television (TV) is a spare time activity for approximately $65 \%$ of school children in Turkey (1). Although smartphones and computers are substituting TV over time, 92.5\% of Turkish children still watch TV on a daily basis (2). TV is present in almost all Turkish households. Moreover, $24 \%$ of families even have more than one TV (3). This situation is not very different in other countries. Indeed, watching TV is often employed by parents as a means of ensuring that their children sit in one place without expos- ing themselves to danger, that is, "staying out of trouble" (4). However, this activity may harbor vulnerability. TV sets can be as heavy as $80 \mathrm{~kg}$, standing on an item of furniture that is usually not adapted to support it safely (5). In addition, children may climb up the furniture, resulting in the tip-over of the entire furniture and leading to various injury scenarios.

Data from the Centers for Disease Control in the USA indicate that accidents and inflicted trauma account for 33\% and 5\%-8\% of childhood deaths, respectively (6). Blunt trauma secondary to falling TVs is 
occasionally reported in the clinical literature (7). Trauma remains the leading cause of death in children over the age of 1 year (8). Injuries sustained in the home account for up to $50 \%$ of cases, and head injury is the most common cause of death in pediatric traumas $(9,10)$.

In this report, we aim to present data regarding the frequency and characteristics of children admitted to a university emergency department in Erzurum, Turkey due to a falling TV between 2000 and 2017. Our secondary aim was, by providing trustworthy research information, to raise awareness on this issue and advise policymakers about the dangers and circumstances involved with a toppling TV, a hazard to which almost all children are exposed.

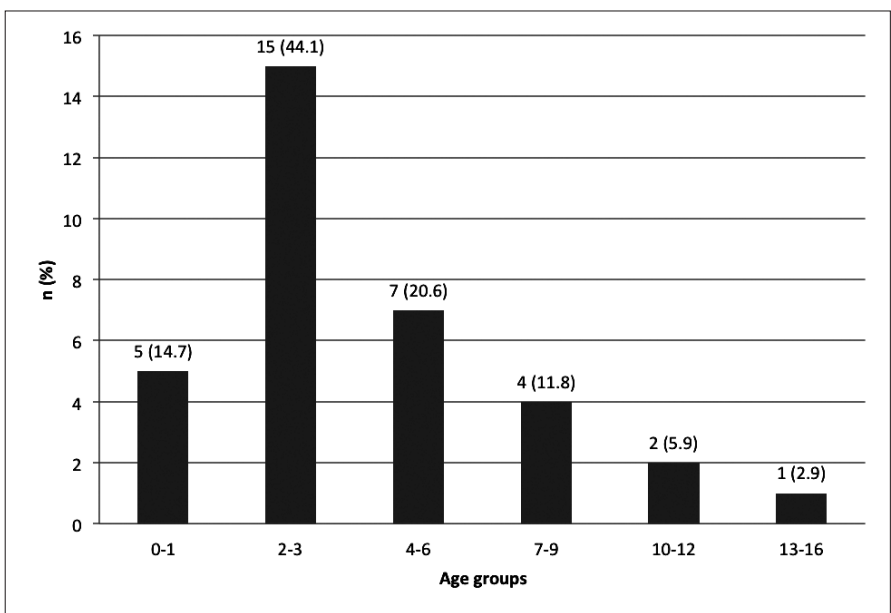

Figure 1. Age distribution of the patients

Table 1. Admission and outcome characteristics

\begin{tabular}{|l|l|l|}
\hline Variables & $\mathbf{n}$ & $\%$ \\
\hline Pediatric Glasgow Coma Scale score on admission & & \\
\hline 15 & 18 & 51.4 \\
\hline $13-14$ & 5 & 14.3 \\
\hline $11-12$ & 2 & 5.7 \\
\hline 9-10 & 2 & 5.7 \\
\hline 7-8 & 3 & 8.6 \\
\hline 4-6 & 2 & 5.7 \\
\hline 3 & 3 & 8.6 \\
\hline Length of hospitalization (days) & & \\
\hline $1-3$ & 18 & 52.9 \\
\hline 4-7 & 11 & 32.4 \\
\hline 8-15 & 4 & 11.8 \\
\hline >15 & 1 & 2.9 \\
\hline Glasgow Outcome Scale score & & \\
\hline 5: low disability & 23 & 67.6 \\
\hline 4: moderate disability & 4 & 11.8 \\
\hline 3: severe disability & 0 & 0.0 \\
\hline 2: persistent vegetative state & 0 & 0.0 \\
\hline 1: death & 7 & 20.6 \\
\hline
\end{tabular}

\section{Materials and Methods}

In this descriptive and analytical file survey, we reviewed our file records between January 2000 and December 2017. The study was conducted at the research and training hospital of Ataturk University School of Medicine, Erzurum, Turkey. The hospital is a tertiary care setting, attracting approximately 400,000 patients annually from a broad geographical area in eastern Anatolia (11).

The inclusion criteria were 0-16-year-old patients admitted to the emergency department with isolated craniocerebral trauma due to TV tip-over and who were referred to neurosurgery clinics. Files of 128 patients meeting the inclusion criteria were retrieved from the hospital's electronic archives. Ethical consent was taken from the Ataturk University School of Medicine, Clinical Research Ethics Board (\#2/56-15/02/2018).

Exclusion criteria comprised patients with minor cranial injury and who were discharged from the emergency department without any need for neurosurgery consultation. After the exclusion of 94 patients $(73.5 \%)$, data for 34 patients $(26.5 \%)$ are presented in the present study.

The following data were extracted from the patient records: age, sex, presenting Pediatric Glasgow Coma Scale (PGCS) score, injured cranial region, radiological findings, admission to the intensive care unit (ICU), length of hospital stay, hospital mortality, and disposition at hospital discharge (12). The outcome at hospital discharge was categorized using the Glasgow Outcome Scale, where a score of 5 is translated as "mild damage with minor neurological and psychological deficits" (13). The parents were inquired about the injury scene and the type of TV.

\section{Statistical analysis}

Results were entered into the computer and analyzed with descriptive statistics. Data were presented as median (minimum-maximum), mean \pm standard deviation, or $\mathrm{n}$ and percentage, where applicable.

\section{Results}

The results from 34 children were analyzed at the end of the analysis of files from over 17 years. The mean age of participants was $4.2 \pm 3.3$ years, and nine (26.5\%) were males and 25 (73.5\%) were females. Most of the patients ( $44.1 \% ; n=15)$ were in the age group of $2-3$ years. The number of cases decreased as age increased (Figure 1).

None of the TVs or the furniture that the TVs were placed on was secured to the wall. Most TVs were with 49-51 cm (19-20 in.) screens $(\mathrm{n}=29 ; 85.2 \%)$. The remaining accidents were with TVs having screen sizes of $51-76 \mathrm{~cm}(20-30 \mathrm{in}$.) $(\mathrm{n}=5 ; 14.8 \%)$. All of the TVs were set at a height between 60 and $120 \mathrm{~cm}$ from the floor. Eighty-eight percent of parents $(n=30)$ said that the child was or may have been climbing on the furniture.

Of the patients, 27 (79.4\%) were hospitalized in the Department of Neurosurgery, whereas $4(11.7 \%)$ were admitted to the ICU. The initial PGCSs of the study population ranged from 3 to 15 with more than half $(51.4 \% ; n=18)$ having full scores. However, five chil- 
Table 2. Physical and radiological findings

\begin{tabular}{|c|c|c|}
\hline Findings & $\mathbf{n}$ & $\%$ \\
\hline \multicolumn{3}{|l|}{ Skull fractures } \\
\hline Linear fractures & 25 & 73.5 \\
\hline Occipital bone & 7 & 28.0 \\
\hline Temporal bone & 6 & 24.0 \\
\hline Frontal bone & 9 & 36.0 \\
\hline Parietal bone & 3 & 12.0 \\
\hline Depressed fractures & 18 & 52.9 \\
\hline Frontal bone & 8 & 44.4 \\
\hline Parietal bone & 4 & 22.2 \\
\hline Occipital bone & 6 & 33.3 \\
\hline Basis Cranii Fractures & 17 & 50.0 \\
\hline Frontobasal & 7 & 41.2 \\
\hline Temporobasal & 6 & 35.3 \\
\hline Occipitobasal & 4 & 23.5 \\
\hline \multicolumn{3}{|l|}{ Intracranial lesion } \\
\hline Extradural hematoma & 13 & 38.2 \\
\hline Subarachnoid hemorrhage & 6 & 17.6 \\
\hline Subdural hematoma & 4 & 11.8 \\
\hline Cerebral edema & 8 & 23.5 \\
\hline Diffuse axonal injury & 2 & 5.9 \\
\hline Pneumocephalus & 13 & 38.2 \\
\hline \multicolumn{3}{|l|}{ Additional lesions } \\
\hline Subgaleal hematoma & 14 & 41.2 \\
\hline Unilateral/bilateral periorbital hematoma & 7 & 20.6 \\
\hline Otorrhea & 3 & 8.8 \\
\hline Otorrhagia & 1 & 2.9 \\
\hline Rhinorrhea & 1 & 2.9 \\
\hline Rhinorrhagia & 4 & 11.8 \\
\hline Superficial scalp maceration & 9 & 26.5 \\
\hline
\end{tabular}

dren (14.3\%) had a PGCS of $<7$. The median duration of hospitalization was 2 days (minimum 1 and maximum 27). Of the patients, $85.3 \%(n=29)$ were hospitalized for less than a week. One case had complex skull fractures and an intracranial hemorrhage and stayed in the hospital for 27 days. Twenty-three patients (67.6\%) were discharged with good outcome scores from the hospital, whereas seven patients (20.6\%) died (Table 1). Three of the mortalities resulted due to severe craniocerebral trauma in the emergency department.

All of the children were radiologically investigated by X-rays of the skull and computed tomography scan. Table 2 shows the physical and radiological findings. One patient, who had hemiparesis and facial paralysis on admission, later developed the syndrome of inappropriate antidiuretic hormone secretion.

\section{Discussion}

Our study demonstrated the severe risk of unsecured TVs in the household with a lack of parent awareness. Trauma is a significant cause of death and disability during childhood. It is responsible for nearly $50 \%$ of all childhood deaths $(7,14)$. Over one-third of the significant childhood injuries occur in the home environment (14). However, blunt trauma secondary to falling TVs is occasionally reported in the clinical literature (7).

Injury by a falling TV unit is not a new problem in developed countries, and the number of injuries following TV tip-over has been increasing over the past decade $(15,16)$. According to Jea et al. (16), the increasing number of casualties from falling TVs is much higher than the increase in the quantities of TV sets sold. Previous studies from Turkey have stressed the increasing danger of TVs toppling (17-19). However, to the best of our knowledge, this is the first report including a detailed description of cases with isolated serious head trauma.

As important as the TV itself, the furniture on which a TV set is situated is of fundamental significance. Attention-raising studies were conducted in the past, suggesting the development of safety criterion and changing the weights of some furniture items to resist tipping (20). Injury prevention counseling and other strategies supporting in-home safety should also include efforts to increase parent awareness. A secure and child-safe location should be ensured for TV sets (8). Attention should be paid to safer design and placement of this ubiquitous product.

Almost all of the parents were blind to the possible risks of a TV at home and unaware that injuries could occur by this mechanism. Of course, "blaming the mom" is not a solution to the problem. However, our study shows that the majority of injuries involved toddlers. Besides, most parents saying that the child was or may have been climbing on the furniture lead our attention to hyperactive toddlers. Patient age as a risk factor is stressed in a previous study (21). Further, a notable increase in domestic accident risks occurs with toddlers (22). Hence, we can confidently claim that childhood home-safety programs should primarily target toddlers.

The main findings of previous studies are similar: craniocerebral injuries caused by TV fall occurring mainly in children between the ages of 1 and 3 years $(7,14,15)$. Our findings are also comparable with those reported in other countries $(4,5,8,14,15)$, suggesting that injuries from TV tip-over occur mainly among children between 1 and 3 years. In the present study, all of the cases were determined to have cranial fractures. Of these fractures, nearly half were multiple and more localized in the occipital bones. Additionally, in more than one-third of the cases, skull fractures were complex, such as separated linear, basilar, numerous, and depressed. According to Dolinak and Matshes (23), complex skull fractures usually occur as a result of severe head trauma and are associated with extradural and subarachnoid hemorrhages, cerebral edema, and diffuse axonal injury, which are additional markers of severe head injury. DiScala et al. (5) reported that many TV tip-overs are caused by children climbing onto unstable TV stands. Further, the design of TV sets has changed toward larger and heavier front screens. 
There is a relationship between falling TV sets and resulting severity of traumas. TVs involved in toppling accidents range in size from 33 to $101 \mathrm{~cm}$ (13-40 in.), and the average height of fall ranges from 75 to $115 \mathrm{~cm}(2.5-3.7 \mathrm{ft})(14,24)$. According to Bernard et al. (8), a 91 $\mathrm{cm}$ (36 in.) TV, which typically weighs $78 \mathrm{~kg}$, falling from $1 \mathrm{~m}$ has the same momentum as a $10 \mathrm{~kg} 1$-year-old child falling 10 stories $(60 \mathrm{~m})$. Even a smaller $51 \mathrm{~cm}$ (19 in.) TV, with a typical weight of $18 \mathrm{~kg}$, has the same momentum as a 1-year-old child falling $3.2 \mathrm{~m} \mathrm{(10ft)} \mathrm{(7).} \mathrm{Jea}$ et al. (16) noted the exceedingly somber and even fatal outcomes of TV sets tipping onto children. DiScala et al. (5) suggested that the consequences of children hospitalized because of TV tip-overs are comparable with that of similarly aged children injured by unintentional blunt trauma, including motor vehicle-related injuries. However, despite the enormous hazard of this condition, this issue has not gained enough attention from researchers, policymakers, or families.

\section{Study limitations}

The present study was a retrospectively designed study, and the number of participants was limited. More studies are needed in larger groups, and prospective studies will present a broader view in these kinds of accidents. Results may change in accordance with local variables; therefore, multicenter studies may broaden their acknowledgement about the present subject.

\section{Conclusion}

It is evident that craniocerebral injuries following TV tip-overs are significant in childhood deaths. The most common injuries were associated with skull fractures and intracranial or extracranial lesions, such as periorbital hematomas, subgaleal hematomas, extradural hematomas, subarachnoid hemorrhages, and brain edema. Injuries from falling TVs were exceptionally high among toddlers. Regrettably, most parents were unaware of this risk, and none took precautions to secure their furniture. Because of these reasons, we suggest that most of the TV-related head traumas are preventable; increased awareness as well as specific recommendations and education can be proposed to minimize the scope and impact of these injuries on children.

Ethics Committee Approval: Ethics committee approval was received for this study from the Ethics Committee of Ataturk University Medical Faculty (2/56; Date: 15.02.2018)

Informed Consent: The study data was obtained from the hospital's electronic archives. Hence, informed consent did not apply.

Peer-review: Externally peer-reviewed.

Author Contributions: Concept - M.C.; Design - M.C., C.C., O.O.; Supervision - M.C., C.C., O.O.; Resources - M.C.; Materials - M.C., C.C.; Data Collection and/ or Processing - M.C.; Analysis and/or Interpretation - M.C., C.C., O.O.; Literature Search - M.C., C.C., O.O.; Writing Manuscript - M.C., C.C., O.O.; Critical Review - M.C., C.C., O.O.; Other - M.C., C.C., O.O.

Conflict of Interest: The authors have no conflict of interest to declare.

Financial Disclosure: The authors declared that this study has received no financial support.

\section{References}

1. Gocen G, Okur A. The effects of TV on speech education. Educational Research and Reviews. 2013; 8: 63.

2. Aral N, Dogan Keskin A. Examining 0-6 Year Olds' Use of Technological Devices from Parents' Points of View. ADDICTA. 2018; 5: 317-48. [CrossRef]

3. Altınkılıç Z, Özkan H. Determination of mothers' attitudes and behaviors about the effects of TV-watching upon the health of children aged 1-6 years. Behcet Uz Cocuk Hast Derg. 2014; 4: 186-94.

4. Sikron F, Glasser S, Peleg K. Children injured following TV tipovers in Israel, 1997-2003. Child Care Health Dev. 2007; 33: 45-51. [CrossRef]

5. DiScala C, Barthel $M$, Sege R. Outcomes from television sets toppling onto toddlers. Arch Pediatr Adolesc Med. 2001; 155: 145-8. [CrossRef]

6. Heron M, Hoyert DL, Murphy SL, Xu J, Kochanek KD, Tejada-Vera B. Deaths: Final data for 2006. Natl Vital Stat Rep. 2009; 57: 1-134.

7. Deisch J, Quinton R, Gruszecki AC. Craniocerebral trauma inflicted by television falls. J Forensic Sci. 2011; 56: 1049-53. [CrossRef]

8. Bernard PA, Johnston C, Curtis SE, King WD. Toppled television sets cause significant pediatric morbidity and mortality. Pediatrics. 1998; 102: e32. [CrossRef]

9. Nagaraja J, Menkedick J, Phelan KJ, Ashley P, Zhang X, Lanphear BP. Deaths from residential injuries in US children and adolescents, 19851997. Pediatrics. 2005; 116: 454-61. [CrossRef]

10. Lescohier I, DiScala C. Blunt trauma in children: causes and outcomes of head versus extracranial injury. Pediatrics. 1993; 91: 721-5.

11. Ataturk Universitesi Saglık Arastirma ve Uygulama Message from the Management. Available from: URL: https://atauni.edu.tr/saglik-arastirma-ve-uygulama-merkezi.

12. Wikipedia. Paediatric Glasgow Coma Scale 2018. Available from: URL: https://en.wikipedia.org/wiki/Paediatric_Glasgow_Coma_Scale.

13. Jennett $B$, Bond $M$. Assessment of outcome after severe brain damage. Lancet. 1975; 1: 480-4. [CrossRef]

14. Scheidler MG, Shultz BL, Schall L, Vyas A, Barksdale EM, Jr. Falling televisions: The hidden danger for children. J Pediatr Surg. 2002; 37: 572-5. [CrossRef]

15. Yahya RR, Dirks P, Humphreys R, Rutka JT, Taylor M, Drake JM. Children and television tipovers: a significant and preventable cause of long-term neurological deficits. J Neurosurg. 2005; 103(Suppl 3): 219-22.

16. Jea A, Ragheb J, Morrison G. Television tipovers as a significant source of pediatric head injury. Pediatr Neurosurg. 2003; 38: 191-4. [CrossRef]

17. Bol O, Cebicci H, Koyuncu S, Sarli B, Gunay N. A hidden household danger: Television. Ulus Travma Acil Cerrahi Derg. 2016; 22: 265-8.

18. Kucuk A, Tumturk A. Television Tip Overs and Head Traumas in Childhood: Results of 36 Children from a Reference Center in Central Anatolia, Turkey. Turk Neurosurg. 2017; 27: 931-4.

19. Guloglu R, Sarici IS, Bademler S, Emirikci S, Issever H, Yanar H, et al. Falling television related child injuries in Turkey: 10-year experience. Ulus Travma Acil Cerrahi Derg. 2012; 18: 61-4. [CrossRef]

20. Drury CG, Czaja SJ, Prabhu GV, Mayne RW, Noland S. Furniture tipping accidents: redesign for prevention. Accid Anal Prev. 1998; 30: 625-39. [CrossRef]

21. Atak N, Karaoglu L, Korkmaz Y, Usubutun S. A household survey: unintentional injury frequency and related factors among children under five years in Malatya. Turk J Pediatr. 2010; 52: 285-93.

22. Kahl H, Dortschy R, Ellsasser G. Injuries among children and adolescents (1-17 years) and implementation of safety measures. Results of the nationwide German Health Interview and Examination Survey for Children and Adolescents (KiGGS). Bundesgesundheitsblatt Gesundheitsforschung Gesundheitsschutz. 2007; 50: 718-27. [CrossRef]

23. Dolinak D, Matshes E. Child abuse. In: Dolinak D, Matshes E, Lew EO, editors. Forensic pathology: principles and practice. 1 ed. Burlington: Academic; 2005. p. 373-87.

24. Ota FS, Maxson RT, Okada PJ. Childhood injuries caused by falling televisions. Acad Emerg Med. 2006; 13: 700-3. [CrossRef] 